Dr MacGowan et al comment:

Our recent study on the use of dipstrips was limited to laboratory use, as noted by $M$ Chessum and Dr Holliman, because factors outside the laboratory are more difficult to quantify in terms of cost and time, while also being outside our direct control. The reduction in laboratory workload and costs alone suggested by both letters may be offset by increased workload in other hospital departments and general practitioners' surgeries. For example, the cost, ordering, and invoicing of dispsticks, and nursing or medical time in performing and recording results should be taken into account. Routine transport costs are unlikely to be changed greatly as collections from clinical areas occur whether eight or 10 samples are taken to the laboratory Whether dipstrips would decrease on-cal costs is not known because the patien population may differ from the general one studied by us. Were the financial savings made on microbiology, clerical and portering services in Mr Chessum's and Dr Holliman's hospital quantified and transferred to the clinical departments now performing these extra procedures?

In our particular laboratory with computer generated reports, clinicians and genera practitioners can gain access to results on-line as they become available. As urine microscopies are authorised on the day of receipt, a reduction in telephone enquiries would not be relevant to us. A factor not discussed by Chessum and Holliman is the possibility that universal routine use of dipstrips by doctors and nurses may increase the number of specimens sent to the laboratory due to unexpected positive findings on dipstrips, which as we know have relatively low predictive value for urinary tract infection. While this does not seem to have been the case in $S$ George's Hospital, it may not be universally true.

The use of dipstrips to screen for urinary infection is more complex than may be initially apparent on superficial evaluation each hospital having to reach its own conclusions on their potential value.

\section{Bone marrow biopsy in non-Hodgkin's lymphoma}

We read with interest the article by Juneja, Wolf, and Cooper. ${ }^{1}$ Our data on this subject were published last year ${ }^{2}$ and were based on a similar number of patients using the same classification for lymphoma, so avoiding nosological problems in comparing analyses of the value of bone marrow biopsy. Our own series consisted of 290 patients; 38 were "miscellaneous" or excluded, leaving a base of 252 patients with non-Hodgkin's lymphoma of all histological grades.

The results of our series and that of Juneja et al are compared in table 1. Rates of positivity were almost directly comparable in low and intermediate grade lymphoma; differences in high grade lymphoma no doubt reflect the small number $(n=9)$ in the Juneja

Table 1 Comparison of series

\begin{tabular}{|c|c|c|c|c|}
\hline \multirow{2}{*}{$\begin{array}{l}\text { Lymphoma } \\
\text { grade }\end{array}$} & \multicolumn{2}{|c|}{ No of cases } & \multicolumn{2}{|c|}{ \% Positivity } \\
\hline & Ours & Juneja et al & Ours & Juneja et al \\
\hline $\begin{array}{l}\text { Low } \\
\text { Intermediate } \\
\text { High }\end{array}$ & $\begin{array}{r}66 \\
165 \\
21\end{array}$ & $\begin{array}{r}105 \\
146 \\
9\end{array}$ & $\begin{array}{l}56 \\
26 \\
43\end{array}$ & $\begin{array}{l}57 \\
23 \\
33\end{array}$ \\
\hline
\end{tabular}

Table 2 Type of infiltration and grade

\begin{tabular}{lllllll}
\hline Grade & Paratrabecular & Nodular & Mixed & $\begin{array}{l}\text { All } \\
\text { focal }\end{array}$ & $\begin{array}{l}\text { (Diffuse, } \\
\text { differentiated, } \\
\text { other) }\end{array}$ & Totals \\
\hline Low & 6 & 9 & 6 & 21 & 16 & 37 \\
Intermediate & 11 & 6 & 14 & 31 & 12 & 43 \\
High & 0 & 1 & 0 & 1 & 8 & 9 \\
Miscellaneous & 0 & 1 & 1 & 2 & 7 & 98 \\
Total & & & & 55 & 43 & \\
\hline
\end{tabular}

series. Overall positivity in our series was $35 \%$ compared with $38 \%$. Almost certainly the difference reflects the larger number of low grade cases in that series. Our interpretation of the data from both series is that the use of bilateral iliac crest biopsy specimens in staging of non-Hodgkin's lymphoma is not justified. In our own series, using single, long core iliac crest biopsy specimens we have the same positivity rate. For iliac crest biopsy specimens we use a Number 8 Islam needle wherever possible and the section is examined histologically at three separate levels $0.5 \mathrm{~mm}$ apart. Average biopsy length is $25 \mathrm{~mm}$ and thus the average area of marrow examined is $150 \mathrm{~mm}^{2}$. Positivity also compares favourably with that reported by Brunning et $a l^{3}$ and Coller ${ }^{4}$-both relatively small series-who are the only other groups to report on the use of bilateral iliac crest marrow biopsy in nonHodgkin's lymphoma.

Biopsy specimen length is important especially when it comes to assessing patterns of disease distribution. In our series the mean biopsy specimen length was $25 \mathrm{~mm}$. In 25 of 52 patients with focal deposition of lymphoma there was a mixed distribution in a paratrabecular and nodular pattern (table 2). Similarly, when diffuse disease was recorded it was sometimes present only in part of the biopsy specimen. The series of Juneja et al also recognises more than one pattern of infiltration. We find it difficult to comment at present on whether any particular type of infiltration is absolutely characteristic of any grade of lymphoma let alone subtype. We suggest that both nodular, non-paratrabecular infiltration, and paratrabecular infiltration are both variants of focal disease; they may well represent similar mechanisms of infiltration.

We agree with the comments made by the authors on bone marrow aspiration and peripheral blood and that when the appearances of marrow biopsy specimens are normal it is extremely rare to find positive peripheral blood or marrow aspirate samples.

The suggestion in the Juneja series that DLC is a special case which might benefit from bilateral biopsy requires further evaluation on large numbers of patients. We are currently undertaking such studies using single biopsy specimens in our own department and intend to publish these in due course. It would then be interesting to make further comparisons.

ROATH AG SMITH D CHOUDHURY Haematology Department, Royal South Hants Hospital, Southampton

1 Juneja SK, Wolf MM, Cooper IA. Value of bilateral bone marrow biopsy specimen in non-Hodgkin's lymphoma. J Clin Pathol 1990;43:630-2.

2 Roath S, Choudhury D, Smith A. Bone marrow biopsy in non-Hodgkin's lymphoma. Haematol Rev Comm 1989;3:626-9.
3 Brunning RD, Bloomfield C, McKenna RW, Peterson L. Bilateral bone marrow biopsies in lymphoma and other neoplastic diseases. Ann Int Med 1975;82:35-66.

4 Coller BS, Chabner BA, Gralnick HR. Frequencies and patterns of bone marrow involvement in non-Hodgkin's lymphoma: Observations on the value of bilateral biopsies. $A J$ Hematol 1977;3:105-19.

Drs Juneja, Wolf, and Cooper comment:

We thank Dr Roath and his colleagues for their interesting comments. We are pleased to note agreement on many points in the two series.

By examining bilateral biopsy specimens we have found the incidence of bone marrow disease in non-Hodgkin's lymphoma to be $38 \%$. We estimate that this has resulted in an increase in positivity rate over unilateral biopsy specimens of $15 \%$ overall and $25 \%$ in cases of diffuse large cell lymphoma. This is comparable with an increase of $10-22 \%$ reported in the previous two major series. ${ }^{12}$ Roath et al have achieved a comparable incidence of $35 \%$ overall in their series using unilateral biopsy specimens. Possible reasons for this discrepancy could be the longer trephine in their series $(25 \mathrm{~mm}$ compared with $19 \mathrm{~mm}$ in ours) and routine examination of three levels of the bone marrow biopsy specimen). Our practice is not to examine multiple levels except in cases with equivocal disease on the first level. It would be helpful if Roath et al would indicate how many cases would have been labelled negative by examining only one and not three levels.

Whether the number of cases of various histological subtypes differed in the two series and contributed to this discrepancy is difficult to ascertain because Roath et al have not mentioned these in their paper. On the basis of their data the use of bilateral biopsy specimens may not be justified if cores $2 \mathrm{~mm}$ or longer are obtained and these are examined at multiple levels. In fact, we make a similar point in our paper: "a question that remains unresolved is whether taking two biopsy specimens from the one side would achieve the same result with less discomfort for the patient." We are examining our own data to see if there is any correlation between marrow disease and the length of the biopsy specimen.

We agree with the findings of Roath et al regarding the occurrence of more than one pattern of marrow disease in many lymphomas and the fact that paratrabecular disease may occur with a focal, nonparatrabecular pattern. With regard to correlation with histology, our data seem to indicate that the paratrabecular pattern is characteristic of follicular lymphoma. In our study the interstitial pattern of disease was also not seen in any case of follicular lymphoma. Of course the possibility of discordant histology has to be borne in mind. The latter was seen in six cases of diffuse large cell lymphoma (DLCL) in our series whereby 
the lymph node biopsy specimen showed large cell lymphoma and the bone marrow biopsy specimen showed paratrabecular aggregates of small lymphoid cells.

1 Brunning RD, Bloomfield C, McKenna RW, Peterson L. Bilateral bone marrow biopsies in lymphoma and other neoplastic diseases. Ann Intern Med 1975;82:35-66.

2 Coller BS, Chabner BA, Gralnick HR Frequencies and patterns of bone marrow involvement in non-Hodgkin's lymphoma: Observations on the value of bilateral biopsies. Am J Hematol 1977;3:105-19.

\section{Rapid ELISA for detecting Epstein- Barr virus infection}

We read with interest the assessment of the rapid ELISA test (Monolert-Ortho Diagnostic Systems, New Jersey, USA) for detecting Epstein-Barr virus infection ${ }^{1}$ and report a case of parvovirus infection which also gave a false positive result with this test.

An 11 year old child presented with spontaneous bruising and had thrombocytopenia (platelets $\left.20 \times 10^{9} / 1\right)$. A bone marrow examination showed increased megakaryocytes, slight haemophagocytosis, and a total absence of red cell precursors. A monospot test was positive and the rapid ELISA test for EBV infection was positive for an acute infection. IgM antibody to parvovirus was present in high titre (greater than 40 units). No EBV IgM antibody was detected, but IgG antibody to EBNA was positive in low titre. Thus despite the positive monospot and Monolert results, there was no serological evidence for an acute EBV infection.

Matheson et al found false positive results with adenovirus, cytomegalovirus, and Toxoplasma gondii infections. Our case suggests that parvovirus infection may also cross-react and we agree that this test has limitations.

M BHAVNANI RB MCGUCKEN J CRASKE

Department of Haematology, Royal Albert Edward Infirmary, District Laboratory Wigan Lane WN1 2NN

1 Matheson BA, Chisholm SM, Ho-Yen DO Assessment of rapid ELISA test for detection of Epstein-Barr virus infection. J Clin Pathol 1990;43:691-3

\section{Cerebral aspergillosis}

Boon $e t$ al $l^{1}$ have reported a seasonal variation in cerebral aspergillosis following liver transplantation, with most cases undergoing postmortem examination between November and April. The authors state that, "no environmental source was identified," and it was suggested that the seasonal variation may simply reflect a higher concentration of spores outside the summer months. The highest aspergillosis counts, however, are usually found in the autumn ${ }^{2}$; most of the cases after liver transplantation occurred between December and March.

The possible role of hospital demolition and maintenance work in outbreaks of this condition has been suggested in two recent papers-one of four patients on a single intensive care unit ${ }^{3}$ and the other of three immunosuppressed patients on a medical ward. ${ }^{4}$ We therefore wondered whether the apparent seasonal variation in liver transplantation might be related to hospital building work and renovations occurring on a "seasonal basis" rather than to external spore counts. This would have clear implications for the risks of infection in immunosuppressed patients and the planning of hospital rebuilding. It would avoid considering restricting liver transplantation to the summer months.

$$
\begin{array}{r}
\text { D CLEMENTS } \\
\text { Llandough Hospital, } \\
\text { Penarth, } \\
\text { South Glamorgan CF6 1XX } \\
\text { S LEADBEATTER } \\
\text { Department of Pathology, } \\
\text { Cardiff Royal Infirmary } \\
\text { IM HARVEY } \\
\text { Department of Community Medicine, } \\
\text { University of Wales, } \\
\text { College of Medicine }
\end{array}
$$

1 Boon AP, Adams DH, Buckels J, McMaster P Cerebral aspergillosis in liver transplantation. J Clin Pathol 1990;43:114-8.

2 Herman LG. Aspergillus in patient care areas. Ann NY Acad Sci 1980;353:140-6.

3 Harvey IM, Leadbeatter S, Peters TJ, et al. An outbreak of disseminated aspergillosis associated with an intensive care unit. Community Med 1988;10:306-13.

4 Dewhurst AG, Cooper MJ, Khan SM, Pallet AP, Dathan JRE. Invasive aspergillosis in immunosuppressed patients: potential hazard of hospital building work. $\mathrm{Br}$ Med J 1990;301:802-4.

\section{Dr Boon comments:}

Dr Clements et al have, quite correctly, drawn attention to the possible role of hospital building and maintenance work in outbreaks of aspergillosis. Despite the current stringencies of NHS capital expenditure, such work still occasionally occurs, but was not a factor in our series. ${ }^{1}$ In fact, two further cases of aspergillosis occurred in the liver unit at the Queen Elizabeth Hospital in the summer of 1989. This prompted a thorough investigation of possible sources of Aspergillus spores by our microbiologists. Heavy contamination of air shafts leading to the liver unit was discovered and the details of this excellent piece of detective work have been presented. (Elliot TSJ, Stone JW, Smith J. Abstract presented at Pathological Society of Great Britain and Ireland, January 1990.)

Clearly, where air contamination is very heavy, Aspergillus spores will lead to infection in susceptible patients, whatever the season This does not conflict with our observations, which are consistent with a greater abundance of $\boldsymbol{A}$ fumigatus spores in winter, wherever the organism might be lurking. One could argue, perhaps, about definitions of "autumn" or "winter," but I suspect there may be variations in the sporulation of $A$ Fumigatus according to climate, and I note the North American source of the reference quoted by Clements et al. ${ }^{3}$

As others have recently testified, ${ }^{3-5}$ aspergillosis is an important cause of morbidity and mortility in many groups of patients. It would, however, be quite as unrealistic to plan hospital rebuilding and maintenance work so as to avoid contamination of specific units at certain times of the year, as to restrict liver transplantation (or treatment of haematological malignancies) to the summer months! The correct approach must surely be effective prophylaxis, avoidance of high dose steroids except where absolutely essential, early diagnosis, safer antifungal treatment and most importantly, a high clinical index of suspicion. I would also emphasise that without the data obtained from necropsy studies such as ours ${ }^{16}$ the true extent of the problem posed by Aspergillus would not be apparent.

1 Boon AP, Adams DH, Buckels J, McMaster P. Cerebral aspergillosis in liver transplantation. Cerebral aspergillosis in liver

2 Seaton A, Robertson MD. Aspergillus, asthm and amoebae. Lancet 1989;i:893-4.

3 Herman LG. Aspergillus in patient care areas. Ann NY Acad Sci 1980;353:140-6.

4 Kelsey SM, Newland AC, Van der Walt J Doran $\mathrm{H}$. Pulmonary aspergillosis in patient with leukaemia. J Clin Pathol 1990;43:783.

5 Shields ML, Joyner $M$, Lee $R$. Invasive aspergillosis in immunosuppressed patients. $B r$ Med J 1990;301:1046-7.

6 Boon AP, Shetty A. Aspergillosis: a 10 year autopsy review. J Pathol 1990;161:340A.

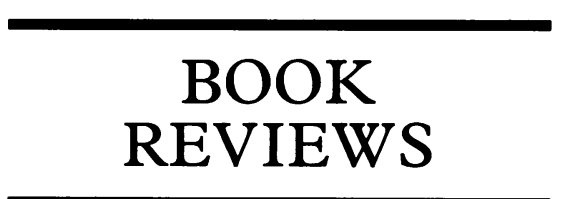

Endocrine Pathology. RV Lloyd. (Pp 260; 232 figs; DM 160.) Springer. 1990. ISBN 30540-97166-1

The stated aim of this textbook is to combine classic histological approaches to endocrine pathology with recent developments in immunohistochemistry and molecular biology. In attempting to achieve this aim in a single author textbook, covering the breadth of the endocrine system, Dr Lloyd has set himself a formidable task. He admits that certain areas have not been covered.

The text is variable. For example, there is a useful short, but comprehensive, discussion of the new classification of pituitary adenomas, based on immunohistochemistry and electron microscopy. In contrast, the problematic area of diagnosing malignancy in adrenocortical tumours is incompletely discussed and referenced. The book is extensively illustrated. There are very elegant colour plates of immunocytochemistry and non-isotopic in situ hybridisation, but some of the black and white photomicrographs are not as crisp as might be expected.

This volume must be compared with others based on a functional approach to the subject, which incorporate more of the clinical and biochemical aspects of endocrine disease. Perhaps to a greater extent than in any other area of pathology, histological diagnosis cannot stand alone. I feel, therefore, that this textbook will not be seriously competitive.

AM McNICOI

The Renal Biopsy. Major Problems in Pathology. Vol 8. 2nd ed. LJ Striker, JL Olson, GE Striker. (Pp 282; £40.) WB Saunders Company. 1990. ISBN 0721630405.

The first edition of this text sits on my shelf but is rarely consulted, for useful information is obtained more easily elewhere. Two of the authors have changed and this is now virtually a new work rather than just a new 